\title{
Development of the GeoCRP for Smart River Management in the Smart City(I)
}

\author{
Bonhyun Koo*, Seunguk Oh, Jaseob Koo, Kyucheoul Shim*
}

Institute of Smart Disaster Management, JBT Corporation, Seoul, Korea

Email address:

kevinkoo@ejbt.co.kr(B. Koo), skcpj@ejbt.co.kr(K. Shim)

${ }^{*}$ Corresponding author

\section{To cite this article:}

Bonhyun Koo, Seunguk Oh, Jaseob Koo, Kyucheoul Shim. Development of the GeoCRP for Smart River Management in the Smart City(I). Journal of Water Resources and Ocean Science. Vol. 10, No. 5, 2021, pp. 155-165. doi: 10.11648/j.wros.20211005.17

Received: October 7, 2021; Accepted: October 25, 2021; Published: October 30, 2021

\begin{abstract}
In this study, we developed the Geo City River Platform (GeoCRP), which regularly collects data on the web and provides the analyzed information by performing flood analysis based on the collected information in order to effectively perform smart city river management. GeoCRP was analyzed and tested in the Eco Delta City (EDC) area. In this platform, a watershed runoff analysis model, a river flow analysis model and an urban runoff analysis model were applied for flood analysis in EDC. GeoCRP can obtain more reliable results by taking a step-by-step approach to urban overflow that may occur in smart cities through the applied model. In addition, since all analysis processes such as data collection, input data generation and result data storage are automatically performed on the web, analysis can be performed, and results can be viewed if an environment that can access the web is established without special equipment or tools. The displayed analysis result is provided visually so that the user can intuitively confirm the information, so it is easy to understand the analysis results. Through this, smart city managers can effectively manage rivers, and it is expected that educational institutions will be able to use it as educational material on urban runoff.
\end{abstract}

Keywords: Watershed Runoff, River Flow Runoff, Urban Runoff, Flood Analysis

\section{Introduction}

Recently, new towns are being developed in locations close to rivers in order to use various water-friendly facilities and trails. In these cities, the importance of urban flood analysis is increasing for the safe life and management of citizens. In addition, extreme weather events such as typhoons or local heavy rains, which occur frequently recently, can cause sudden damage by rapidly changing the water level and runoff in the watershed.

In downtown areas where many people and facilities are concentrated, it is necessary to predict and prepare for flooded areas in order to reduce such damage [1]. Analysis of flooded areas in cities is possible through urban runoff analysis, but it is difficult to derive accurate flooded areas with only a single analysis. Therefore, for high-accuracy prediction of flooded areas in cities, it is necessary to derive results by connecting watershed runoff analysis, river flow analysis, and urban runoff analysis.

A lot of research has been carried out abroad to predict the flooded area within the city. There is a case of establishing an operating system in Houston, Texas, USA by linking HEC-HMS and HEC-RAS based on radar rainfall data [2]. In the Wisom River in the UK, flood overflow was analyzed using a one-dimensional finite difference model [3], and the flood overflow area was derived by combining the topographic data of TIN model and the HEC-RAS model [4]. In Spain's Zucca River, a study was conducted to analyze the flood control near the floodplain through the Geographic Resources Analysis Support System (GRASS) model [5]. In the US, National Weather Service (NWS) used the rainfall-flood relationship based on rainfall observation data for flood prediction through an automatic LFWS (Local Flood Warning System) installed by the US Bureau of Reclamation (USBR) in northern California [6]. In addition, in the Susquehanna River basin in the US, Susquehanna Flood Forecast and Warning System (SFFWS) is operated to perform flood forecasting based on pre-established rainfall and water level observation data and satellite data. As shown in the research case, overseas studies are continuing to provide forecasting warnings by 
predicting flood flooding areas through a combination of various information and models.

In addition, various studies are being conducted in Korea. Among them, K-water divided the Soyang river dam into sub basins and used GRASS to build necessary date for the runoff module. Dike overflow and overflow flood analysis was performed using the Dynamic Wave Operation Model (DWOPER) model and expressed in GIS [7]. In the Cheonggyecheon Basin restored as an urban river, a flood prediction model based on hydrological observation was presented, and the applicability of the model was reviewed through actual data [8]. To estimate the amount of urban flooding, the expected flooding site was estimated using the SWMM model, and the expected flooding damage was analyzed in connection with the GIS database [9, 10]. However, in these studies, it was difficult to expect high accuracy because it was not possible to analyze the overall flood flow by performing analysis through just local information and one model. In order to solve these problems, research was conducted to analyze the flood situation by linking HEC-HMS and HEC-RAS or HEC-RAS and SWMM models [11-13]. However, approaches that linked these two models were difficult to analyze the flow of water from upstream to the city from the upstream of the river, so it was difficult to estimate the appropriate amount of flood.

In this paper, we developed a GeoCRP that can perform urban flood analysis by linking watershed runoff, river flow and urban runoff analysis models for efficient smart city flood management. GeoCRP collects and provides data required for flood analysis and provides high-accuracy urban runoff results by linking the output and input information of three models based on the collected data.

The rest of this paper is organized as follows. Section 2 describes the structure and data flow of the flood analysis linkage module, the models applied for each stage and the area where each model is applied. Section 3 provides the model applied to each module, how to configure input information, and the expression of analysis results through modules. Section 4 concludes this paper.

\section{Flood Analysis Linkage Module Structure}

In this Section, before explaining the structure of the flood analysis linkage module, the composition of GeoCRP is briefly described.

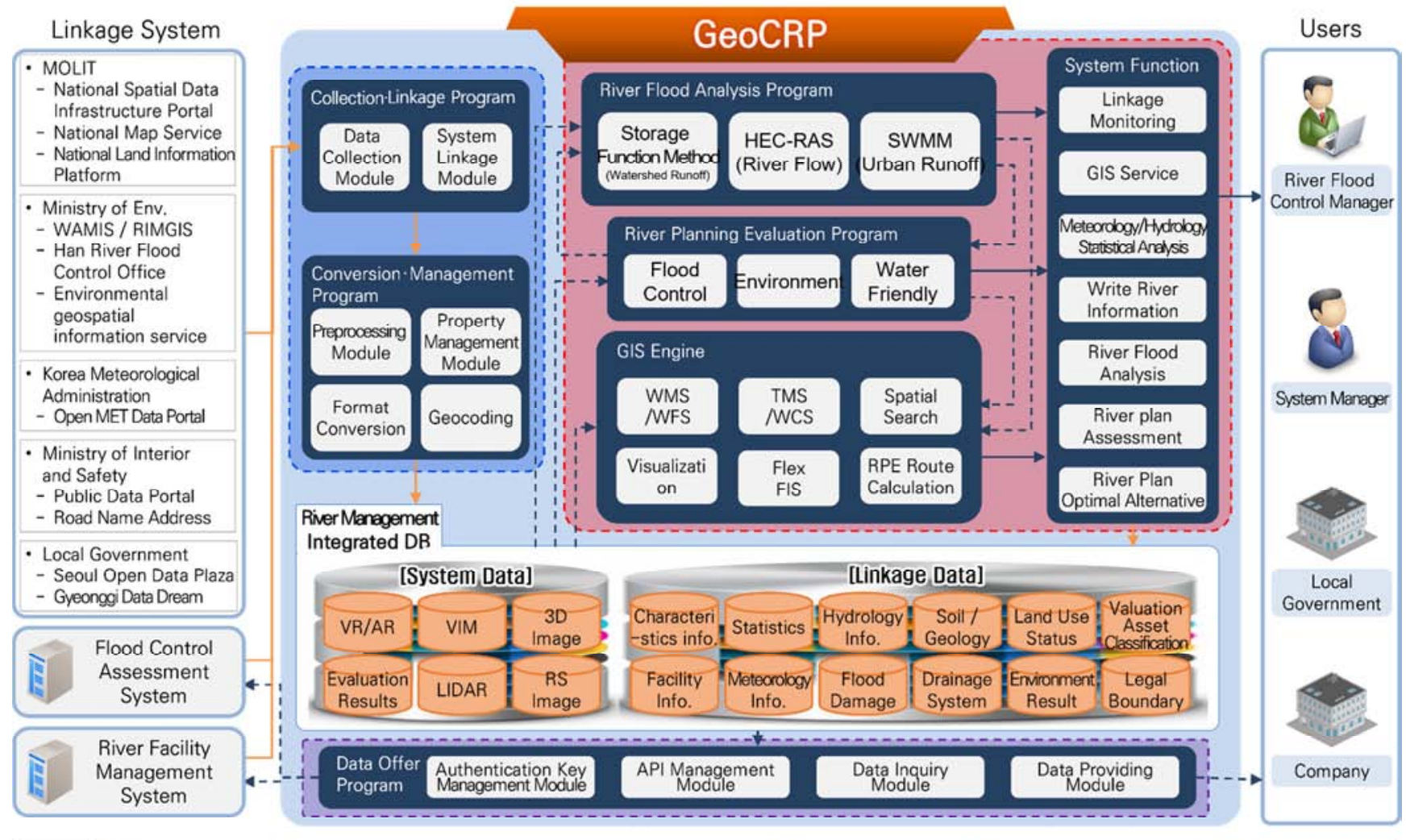

Program — Process Flow —- Data Saving Flow --- Data Reference Flow

Figure 1. GeoCRP Block Diagram.

\subsection{The Composition of GeoCRP}

GeoCRP is composed of collection system, analysis \& display system and providing system as figure 1 . The collection system collects data provided by various institutions and systems, transforms it according to each data type and stores it in the integrated DB. The providing system 
provides information stored in the integrated database to various organizations and systems, and manages data requests through authentication keys. Finally, the analysis \& display system consists of a river flood analysis program, a river evaluation program, a GIS engine and system functions for display. This study focuses on the river flood analysis program among the various programs of the analysis and display system.

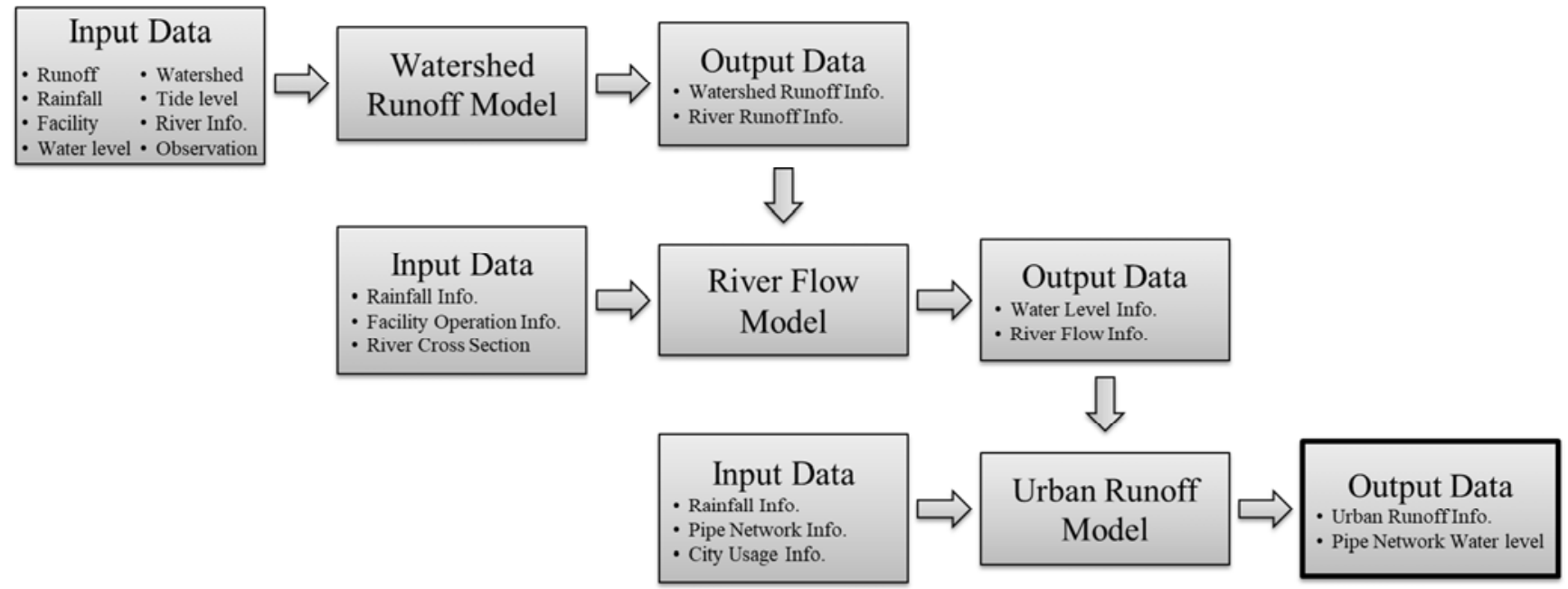

Figure 2. Urban flood analysis data flow.

\subsection{Analysis Module Structure Design for Flood Analysis}

In order to effectively perform the urban flood analysis of smart cities, it is necessary to link several models as mentioned in the introduction, rather than simply analyzing river hydraulics or urban pipe networks. Figure 2 shows the data linkage structure of several module to increase the accuracy of flood analysis in a smart city. To increase the accuracy of urban runoff analysis in smart city, water level and flow rate were applied through river flow analysis around city. Also, in order to increase the accuracy of river flow analysis, the amount of outflow at the exit point of the basin where the river begins was derived through the watershed runoff analysis of a river basin.

In this study, to derive the flood overflow area within the urban area, a watershed runoff analysis is first performed in the river basin. After that, based on the runoff information derived from the watershed runoff analysis, the river flow analysis is performed on the rivers near the urban area. Through river flow analysis, water level and river flow information can be obtained for each river section, and the final urban runoff is analyzed by using the information as the pipe network exit point information in the urban runoff analysis. Through this analysis, surface runoff in urban areas can be obtained, and information about flooded areas in the city can be obtained when a flood occurs. Information on flooded areas is derived based on the amount of runoff in the city and is provided through GIS in the system so that users can intuitively understand it.

\subsection{Analysis Area by Module}

In this study, the analysis area was selected as shown in the Figure 3 to perform analysis of the entire stream from the river upstream to the EDC, which is the final analysis goal.
Figure 3 (a) shows a watershed runoff analysis area, and a watershed runoff analysis is performed on the entire Nakdong river basin. Based on the results of the watershed runoff analysis model, the river flow analysis model analyzes the river area around EDC in Figure 3 (b). In Figure $3(\mathrm{C})$ EDC area, which is the final goal, the amount of runoff in the area is analyzed through the urban runoff analysis model.

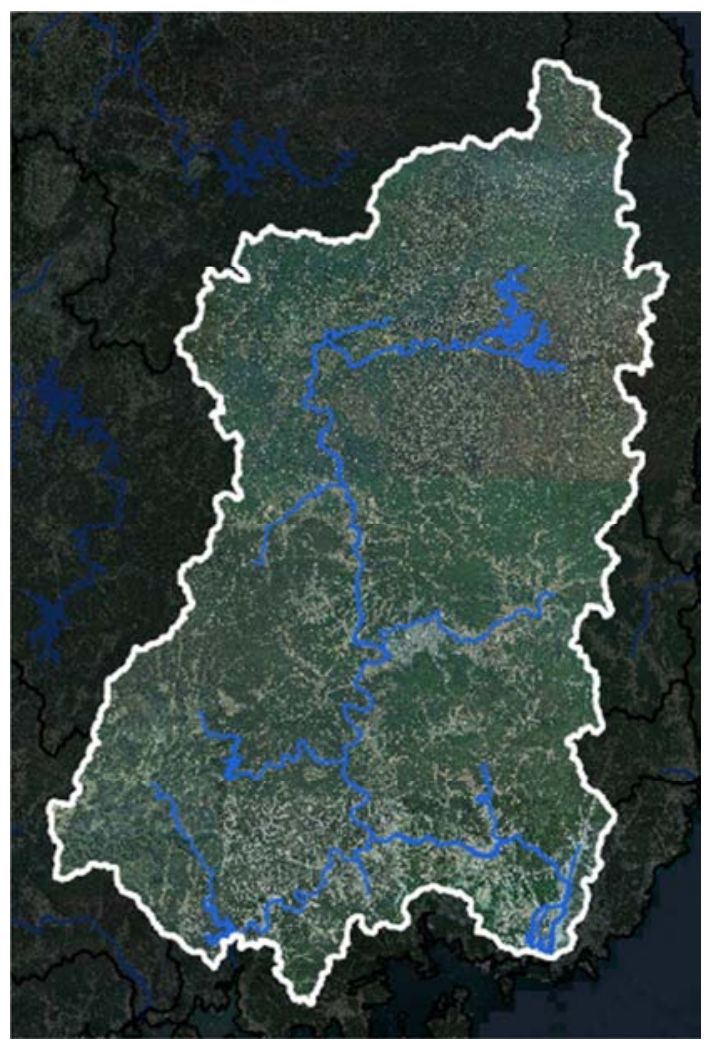

a) Nakdong river basin 


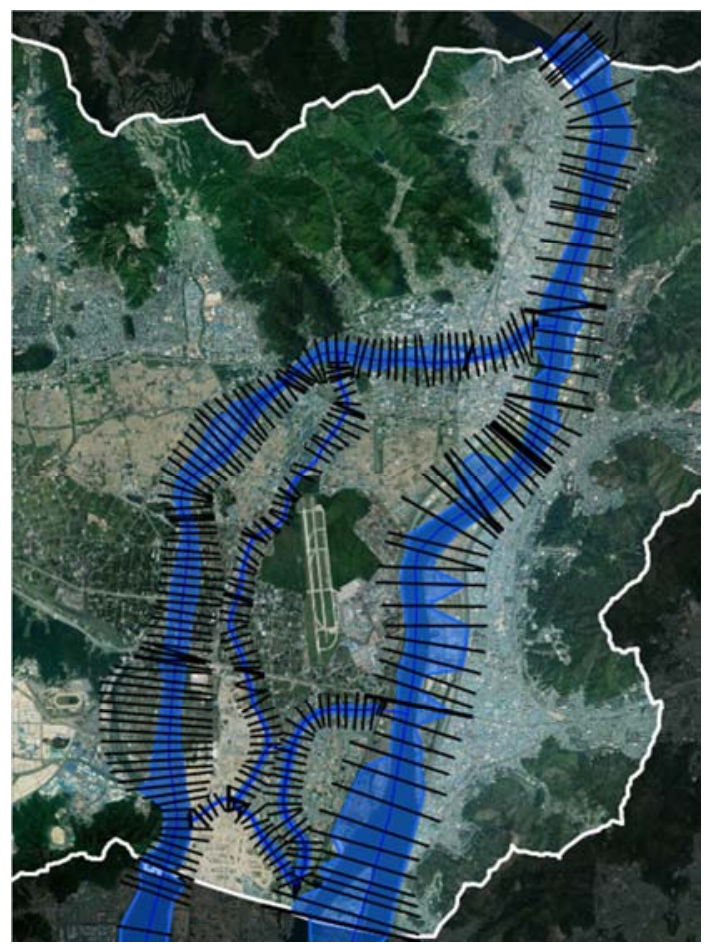

(b) Rivers around EDC

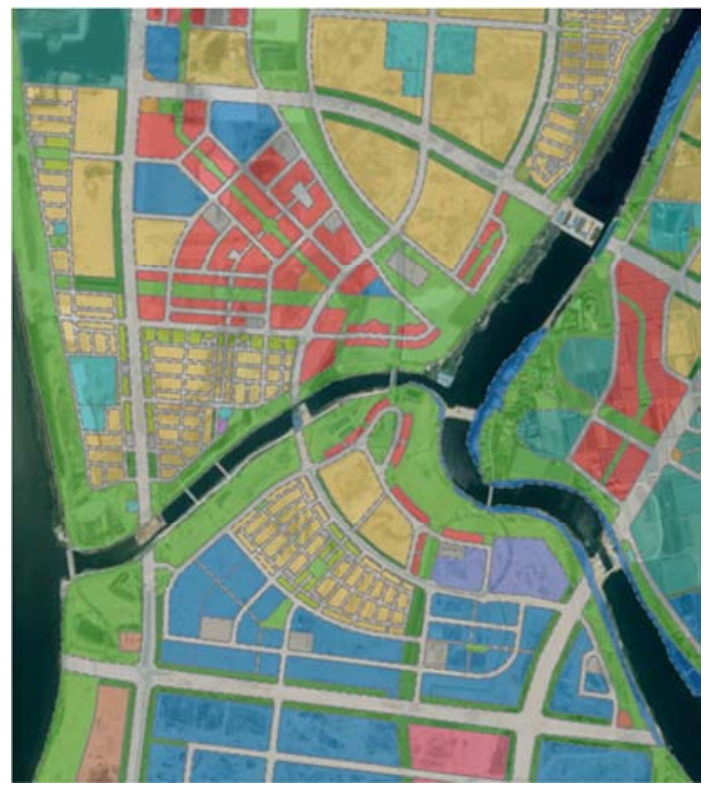

(c) Busan delta region

Figure 3. Analysis area

\subsection{Applied Models for Each Module}

In this paper, three modules are developed and applied to the platform. The model applied to each module was selected by considering the efficiency and accuracy of the platform due to the characteristics of the platform that provides various functions. In the watershed runoff modules, a model with low complexity and appropriate performance was considered because the module needs to analyze a large area. The storage function model is adopted for the watershed runoff analysis module, and the model is also used by the
Nakdong River Flood Control Center, so the stability of the performance is guaranteed. For river flow analysis module, the HEC-RAS model developed by the US Army Corps of Engineers was applied to analyze the flow of the entire river. Finally, in the urban runoff analysis module, the EPA SWMM made by the US Environmental Protection Agency was adopted to identify the water flow in the city pipe network and to analyze the runoff amount to the city. The three selected models are designed to derive the required result in each step and return the input value of the next step.

\section{Flood Analysis Linkage Module Structure}

\subsection{Watershed Runoff Analysis Module}

\subsubsection{Storage Function Model}

The Storage function method, which was proposed by Kimura Toshiaki in 1961, determines the amount of flood runoff by calculating the continuity equation for the momentum of the flood wave in the storage function representing the relationship between runoff and storage. In Korea, since it was introduced into the Han River flood forecast system in 1974, it has been adopted and used in the Nakdong River, Geum River, and Seomjin River flood forecast systems.

The storage function model has characteristics that can be interpreted in consideration of the characteristics of static flow, which is a characteristic of flood runoff occurring in the natural state. In addition, it is easy to derive parameters such as various variables based on past rainfall and runoff data, and non-linearity, a characteristic of general flood runoff, is considered.

\subsubsection{Analysis Module Input Information Configuration}

In order to analyze a watershed runoff, it is necessary to construct four types of information: divided watershed, divided channel, hydrological observation, and facility information. For the divided watershed information, 195 standard watersheds described in version 3.0 of the water resource unit map of WAMIS (Water resources Management Information System) were used. The divided watershed information includes basic watershed information and parameter information for calculating effective rainfall and runoff for each watershed. Second, the divided channel information includes channel information, channel connection information and parameter information for estimating the outflow occurring in the channel. The above two items are values having regional characteristics and represent values that do not change.

On the other hand, hydrological observation information and facility information that change depending on the time and situation of analysis are as follows. The hydrological observation information includes information on the precipitation, water level and observation station that observes the tide. Observation information is divided into information having the location and specification of the observatory and information having observation information. 
The observation information basically uses 10-minute data and can be changed according to the user selection. The facility information has information about dams, reservoirs and weirs that exist in rivers. In particular, in the case of dams and reservoirs, information on facility specifications for facility operation, H-V (water level-capacity) relationship, and H-Q (water level-flow rate) relationship information of overflow structures are included.

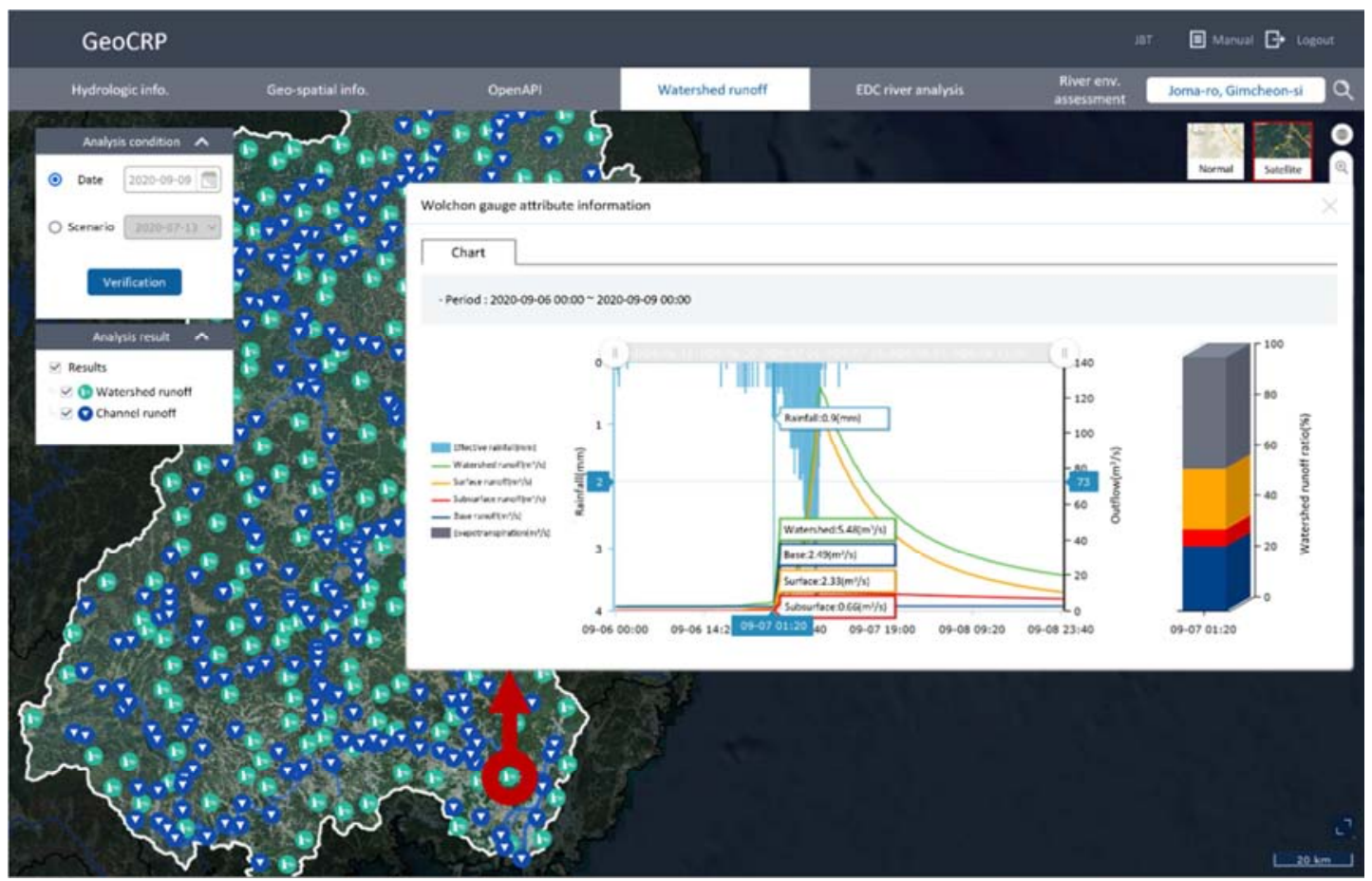

Figure 4. Watershed Runoff Analysis Result.

\subsubsection{Expression of Analysis Results}

The watershed runoff analysis result is derived based on the watershed information and river channel information used in composing the input information. Therefore, the analysis results for the analysis period set by the user are calculated based on the outflow points of each watershed and channel, and the calculated results are stored in the database and provided through the platform. Figure 4 shows the results of the analysis of watershed runoff stored in the database through the platform. When the analysis date in the upper left is selected, the icon shown in the analysis results is displayed on the map as shown in the picture. If user select the watershed outlet point of the Wolchon water table indicated by the red circle in the figure, a pop-up window appears as shown in the figure. The results of the watershed runoff are expressed as a graph showing time series information of rainfall and runoff information as shown in the figure, and a bar graph showing the runoff composition ratio of the day according to the user's mouse position in the graph.

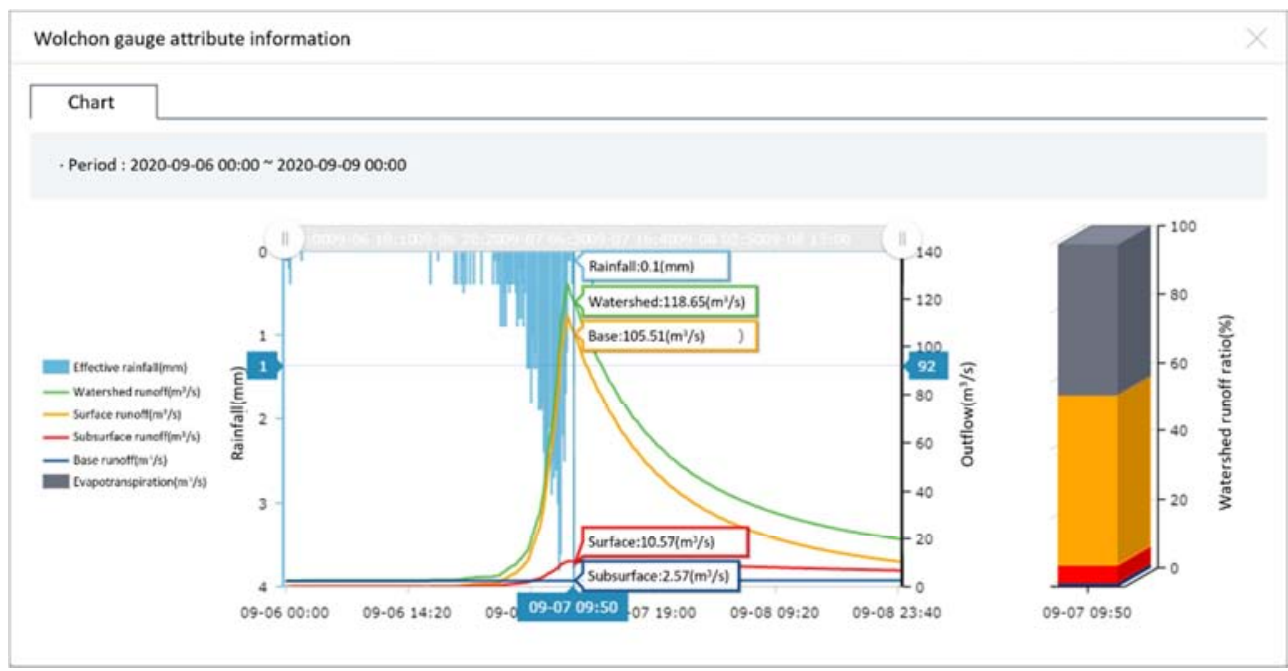

(a) Rainfall, Watershed Runoff 
Wolchon 202264(no.25) attribute information

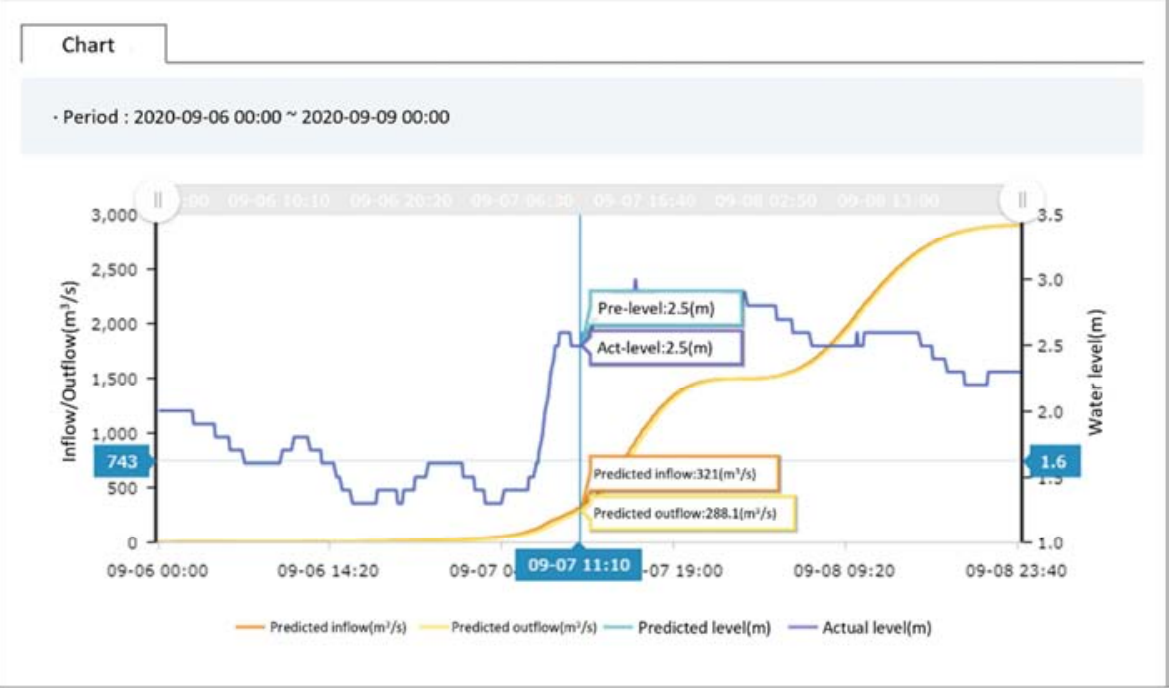

(b) Rainfall, Channel Runoff

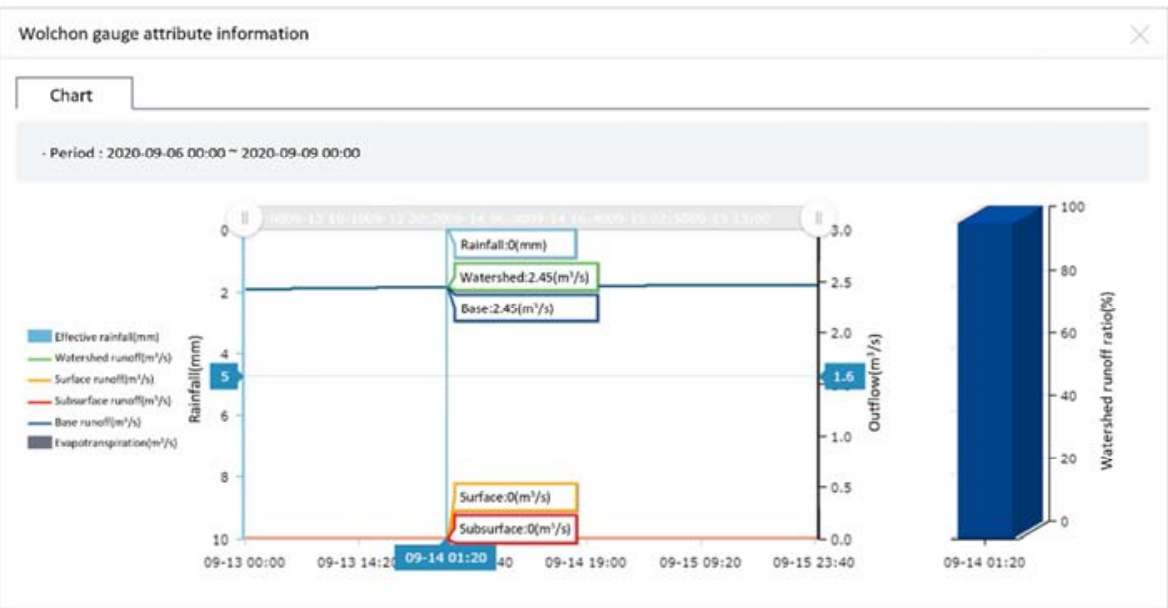

(c) No Rainfall, Watershed Runoff

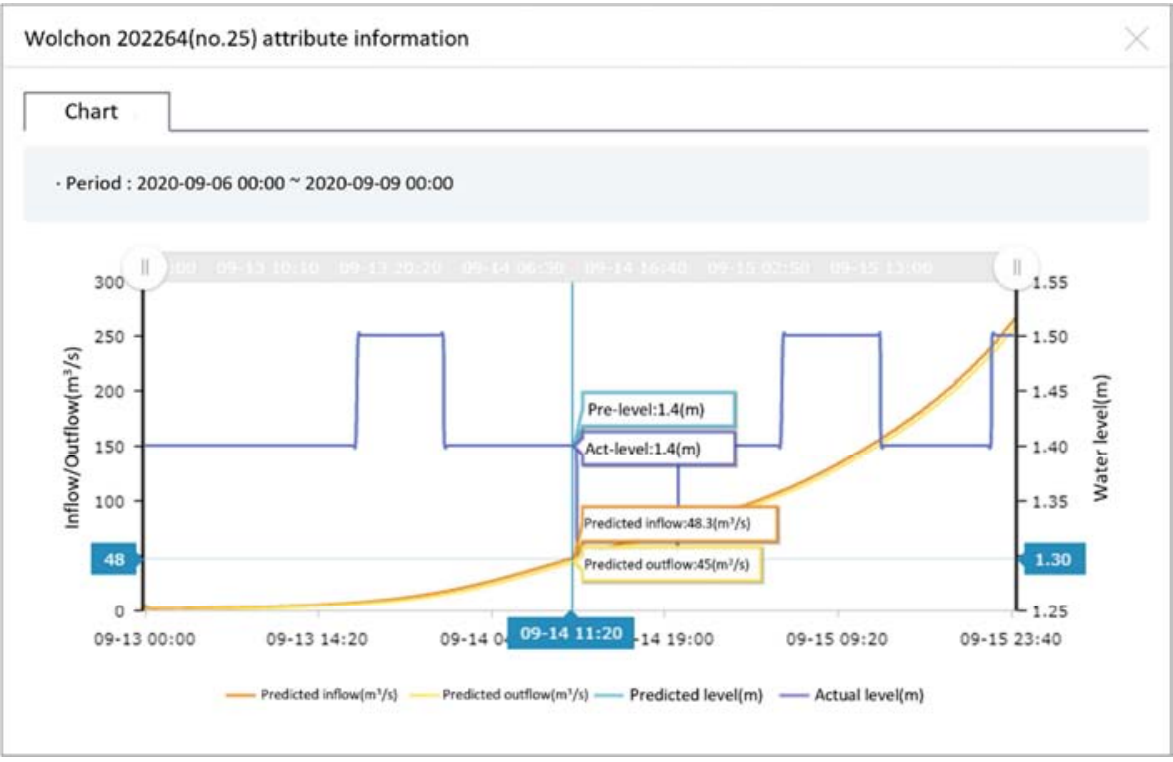

(d) No Rainfall, Channel Runoff

Figure 5. A Comparison of Watershed Runoff Analysis Results. 
Figure 5 shows a figure comparing the results of watershed and channel runoff analysis by rainfall situation derived from the analysis of watershed runoff module. Figures 5 (a) and (b) show the situation where rainfall occurred, and (c) and (d) show the analysis results for the situation where there is no rainfall. Also, (a) and (c) provide watershed runoff information, and (b) and (d) provide channel runoff information as water level, inflow and outflow time series information.

Among (a) and (c) representing watershed runoff, (a) is the result of watershed runoff when rainfall occurs. As rainfall occurs, a large amount of ground runoff and a small amount of ground runoff increase at the corresponding watershed runoff point, thereby increasing the total watershed runoff, and then it shows the runoff gradually decreases as the rainfall decreases. In addition, compared with Figure 5, in the right watershed runoff composition ratio bar graph, it shows the ground runoff increased, and the base runoff amount was relatively significantly lowered. On the other hand, in Figure 5 (c), where there is no rainfall, it shows the general base runoff is the total watershed runoff, and the change is insignificant.

In Figures 5 (b) and (d) showing the channel runoff, it shows the water level increases close to $3 \mathrm{~m}$ from the date of the increase in rainfall in (b), an analysis of the situation without rainfall. In (d), it has a flat-water level value between 1.4 and $1.5 \mathrm{~m}$ and shows a small amount of change. Also, the values for inflow and outflow shown in the two figures remain at $300 \mathrm{~m}^{3} / \mathrm{s}$ without rainfall, while increasing to 3,000 $\mathrm{m}^{3} / \mathrm{s}$ in the case of rainfall.

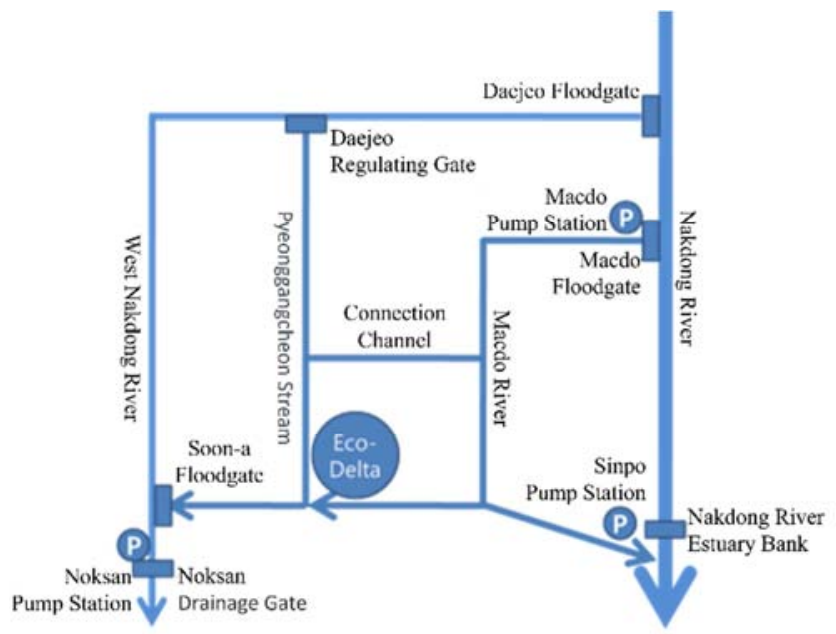

Figure 6. West Nakdong River Hydrosphere Stream Network.

\subsection{River Flow Analysis Module}

\subsubsection{River Flow Analysis Model}

In this study, the HEC-RAS model developed by the U.S. Army Corps of Engineers is used to perform river flow analysis. The HEC-RAS model is a comprehensive river analysis model that not only calculates the point-variant water surface curve in the steady-flow state in natural or artificial rivers, but also provides the function of analyzing irregular currents and similar phenomena. In this study, river flow analysis around EDC is performed by linking the model.

\subsubsection{Analysis Module Input Information Configuration}

The final purpose of this study is to analyze urban runoff in the EDC delta area. Therefore, as shown in figure 3 (b), the input information of the module is composed of the Macdo river and Pyeonggangcheon stream that are in contact with the target area, and the west Nakdong and Nakdong rivers that can affect the corresponding area. The river flow analysis module input information consists of river network, boundary conditions, and rainfall information.

The river network data are unchanging data and include geographic information about the analyzed river. In this study, west Nakdong river system national river master plan [14] and Nakdong river basin plan [15] of the Ministry of Land, Infrastructure and Transport were used to construct river geographic information among river network information. The lack of geographic information was supplemented using Digital Elevation Model (DEM). Figure 6 shows the simplified west Nakdong River water system according to the hydraulic characteristics of the target rivers. The basic stream network was composed based on the model by linking the coordinate information, and the information of about the stream network was created by adding the cross-section and extension information.

The second input information includes the estuary bank, sluice gate, and pumping station information as boundary conditions. The estuary bank information includes the Nakdong River estuary bank and the west Nakdong River estuary bank information. The opening and closing conditions of the estuary were established according to the information such as the planned flood level of the river master plan. Within the analysis area, there are Soon-a floodgate and Daejeo regulating gate to separate the Macdo River, Pyeonggancheon Stream and the West Nakdong River, and Daejeo and Macdo floodgate to supply environmental water to the West Nakdong River and Macdo River. Finally, the pumping station is also included in the boundary condition. In the analysis area, there are the Noksan pumping station, the Sinpo pumping station and the Macdo pumping station that discharge from the river to the southern sea or the main stream. In addition, the water level and runoff information about the starting point of the Nakdong river was applied based on the results of the watershed runoff analysis to compose the input data.

The last input information, the rainfall information, was reflected in the same information as the rainfall information used in the watershed runoff for the analysis target area.

Based on the data described above, the river flow analysis module in the platform composes the input data to be used for HEC-RAS, and operates HEC-RAS based on the input data. The results derived through HEC-RAS is analyzed through the module, stored into the database and expressed within the platform. The river flow analysis results are described below. 


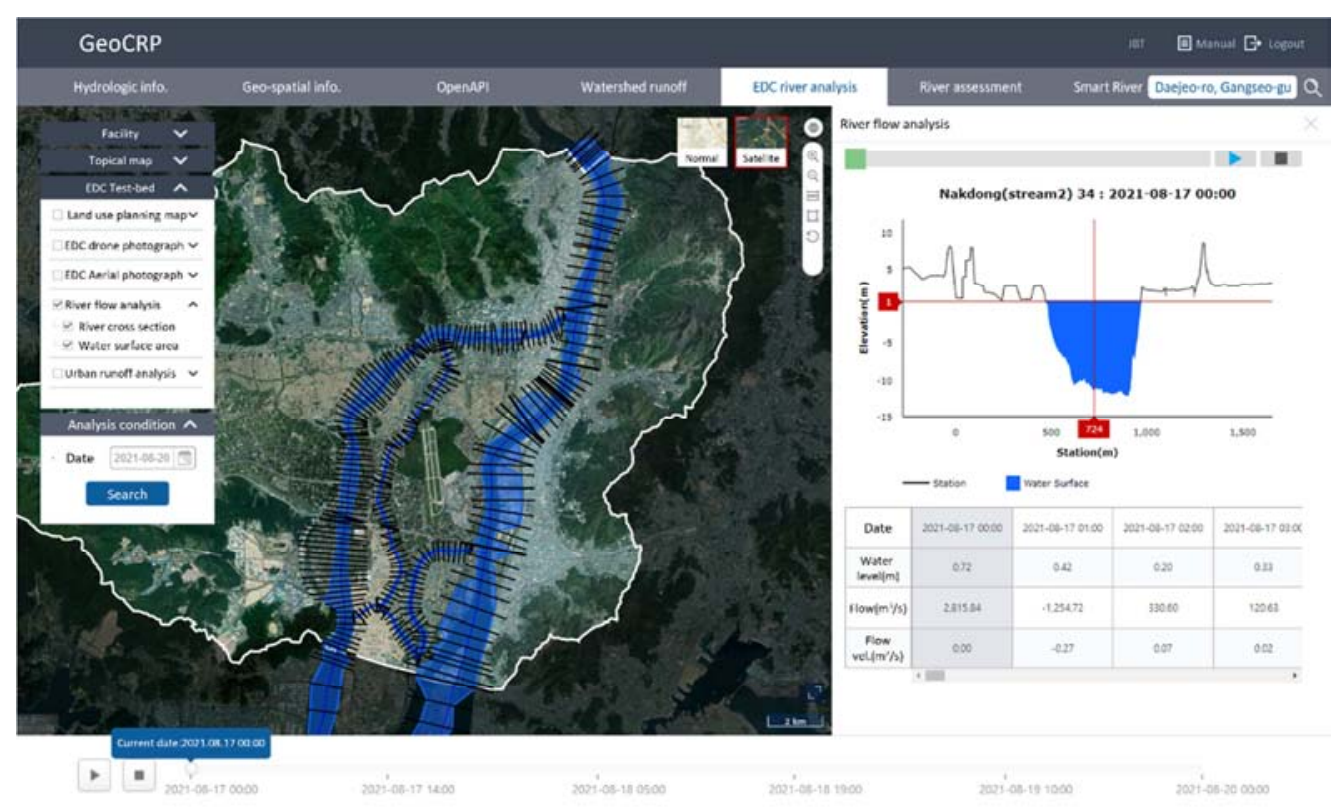

Figure 7. River Flow Analysis Result.

\subsubsection{Analysis Result Expression}

The river flow analysis result is displayed on the screen as shown in Figure 7 based on the cross-section information used as input information. Therefore, the result of river flow analysis is derived according to the river section as shown in the figure. The analysis result stored in the database is provided by composing the water surface area as the river level information in the cross section as shown in the figure. When a river section is selected, the water level for the river section is expressed as a graph as shown on the right side of the figure, and information about the water level, flow rate, and flow velocity is provided in a table. The animation bar located at the bottom and top right of the figure provides an image of changing the water level of the river section and the surface area of the map with the passage of time.
The water level for each river section derived from this analysis is used as the water level information at the outlet of the pipe network among the input data of urban runoff, which is the final goal of this study.

\subsection{Urban Runoff Analysis Module}

\subsubsection{Urban Runoff Analysis Model}

For urban runoff analysis, EPA SWMM made by the US Environmental Protection Agency was adopted as an analysis model in this study. EPA SWMM is a rainfall-runoff-surface runoff simulation model. This model can be used to predict the hydrological characteristics such as surface runoff, groundwater and evaporation caused by rainfall in urban watersheds, and the amount of runoff to pipes and rivers such as irrigation channels and open channels.

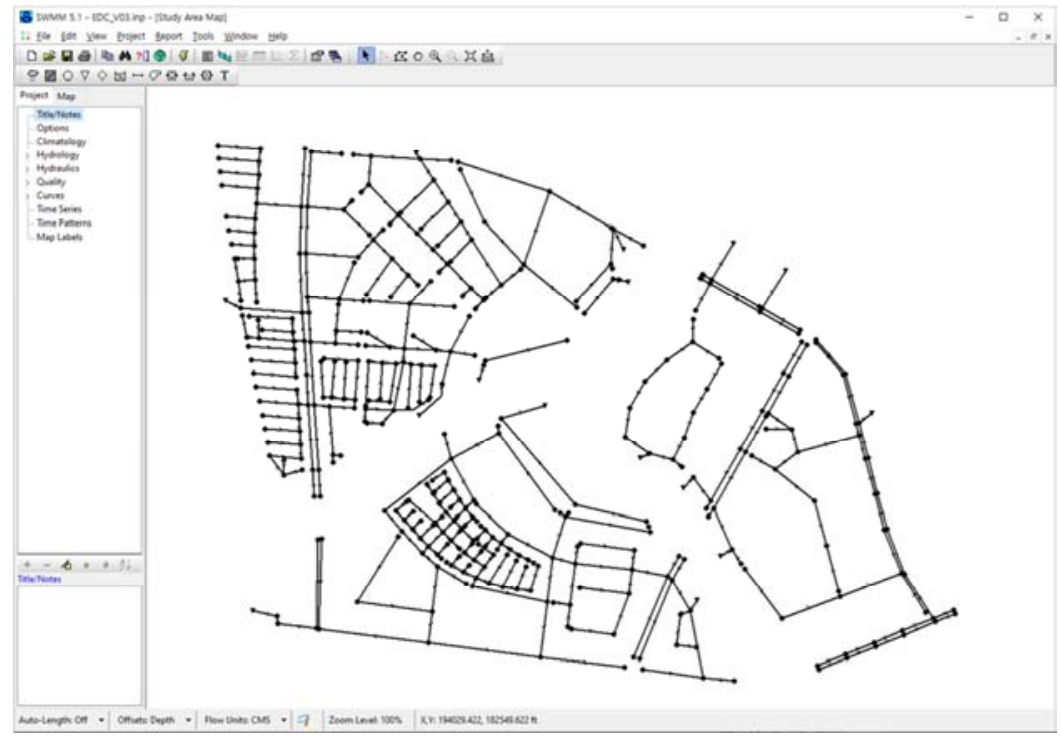

Figure 8. Urban Runoff Analysis Model. 


\subsubsection{Analysis Module Input Information Configuration}

The target area of urban runoff analysis is limited to the delta area of Figure 3(c) among EDC areas. The location and information on the water pipe network and manholes in the current target area were configured as shown in Figure 8 based on the EDC design and drawings. The input information of
EPA SWMM consists of one input data, and it is created based on the information on the 51 items presented in Table 1. In this study, the input data was composed of the options of the items with ' $\mathrm{Y}$ ' in the 'Use' column among the options presented in the table.

Table 1. EPA SWMM Input File Options.

\begin{tabular}{|c|c|c|}
\hline Section Name & Use & Description \\
\hline TITLE & $\mathrm{Y}$ & Name of simulation \\
\hline OPTIONS & $\mathrm{Y}$ & Analysis options \\
\hline REPORT & $\mathrm{Y}$ & Select items for reporting \\
\hline FILES & $\mathrm{N}$ & Select files using to input file and storing to output file \\
\hline RAINGAGES & $\mathrm{Y}$ & List of rain gauges \\
\hline EVAPORATION & $\mathrm{Y}$ & Information of evapotranspiration amount \\
\hline TEMPERATURE & $\mathrm{N}$ & Daily temperature, monthly shift, etc. \\
\hline SUBCATCHMENTS & $\mathrm{Y}$ & Information of subcatchment \\
\hline SUBAREAS & $\mathrm{Y}$ & Pervious / impervious information for subcatchments \\
\hline INFILTRATION & $\mathrm{Y}$ & Permeation parameter about subcatchments \\
\hline LID_CONTROLS & $\mathrm{N}$ & Low Impact Development information \\
\hline LID_USAGE & $\mathrm{N}$ & LID connection information definition for subcatchments \\
\hline AQUIFER & $\mathrm{N}$ & Supplies parameters for each unconfined groundwater aquifer \\
\hline GROUNDWATER & $\mathrm{N}$ & Supplies parameters that determine the rate of groundwater flow \\
\hline GWF & $\mathrm{N}$ & Groundwater flow equation \\
\hline JUNCTIONS & $\mathrm{Y}$ & Identifies each junction node such as manhole \\
\hline OUTFALLS & $\mathrm{Y}$ & Nodes located at the boundary of the final downstream \\
\hline DIVIDER & $\mathrm{N}$ & nodes where two pipes are connected to distribute the flow \\
\hline STORAGE & $\mathrm{N}$ & Storage nodes \\
\hline CONDUITS & $\mathrm{Y}$ & Pipe, link definition \\
\hline PUMPS & $\mathrm{N}$ & Drainage links \\
\hline ORIFICES & $\mathrm{N}$ & Link information to control flow with orifice links \\
\hline WEIRS & $\mathrm{N}$ & Link information such as bank (reservoir) \\
\hline OUTLETS & $\mathrm{N}$ & Drainage system outlet flow control link information \\
\hline XSECTIONS & $\mathrm{Y}$ & Pipe structure information \\
\hline LOSSES & $\mathrm{Y}$ & Pipe leak rate definition of manhole loss factor, flap gate, etc. \\
\hline TRANSECTS & $\mathrm{N}$ & - \\
\hline CONTROLS & $\mathrm{N}$ & Define whether pumps and regulators are regulated at specific nodes and links based on simulation time and conditions \\
\hline POLLUTANTS & $\mathrm{N}$ & Pollutant definition \\
\hline LANDUSES & $\mathrm{N}$ & Land use definition by watershed \\
\hline BUILDUP & $\mathrm{N}$ & Defines the rate at which pollutants accumulate on different lands during rainfall \\
\hline WASHOFF & $\mathrm{N}$ & Defines the speed at which pollutants are washed off other lands during rainfall \\
\hline TREATMENT & $\mathrm{N}$ & The degree to which pollutants are introduced and treated at a specific node \\
\hline INFLOW & $\mathrm{N}$ & Water and pollutant inflow information from a sluice gate on a specific node \\
\hline DWF & $\mathrm{N}$ & - \\
\hline RDII & $\mathrm{N}$ & Definition of flooded/inflow hydrograph according to rainfall at a specific node \\
\hline HYDROGRAPH & $\mathrm{N}$ & Define parameters that determine infiltration/inflow according to rainfall \\
\hline CURVES & $\mathrm{N}$ & - \\
\hline TIMESERIES & Y & Time series data definition \\
\hline PATTERNS & $\mathrm{N}$ & - \\
\hline MAP & $\mathrm{Y}$ & Map area and unit information \\
\hline COORDINATES & Y & Node coordinate information \\
\hline VERTICES & $\mathrm{Y}$ & Link coordinate information of vertex point \\
\hline POLYGONS & $\mathrm{Y}$ & Watershed coordinate information \\
\hline SYMBOLS & $\mathrm{Y}$ & Rain gauge location information \\
\hline LABELS & $\mathrm{N}$ & Label location \\
\hline BACKDROP & $\mathrm{N}$ & Background image coordinate information \\
\hline
\end{tabular}

As the input data, EDC, the target area, is under construction, so information on the watershed, manhole and water pipe network was constructed based on the initial EDC design. For the rainfall information, a rain gauge was set, and the rainfall information of the rain gauge set for each watershed was reflected. In this study, one rainfall information is used because the analysis area is a local area. Rainfall information was built based on the rain gauge setting 
information in the time series option. As the target area of this study is limited to the EDC delta area, the pipe network connected to the upper area is assumed to be an exit point.

In this study, based on the input data described above, the input file of the EPA SWMM is created in the urban flow analysis module of the platform and analysis is performed through the simulation execution command.

\subsubsection{Analysis Result Expression}

The urban runoff analysis result is derived on the map based on the manhole and water pipe network data used as input information. EPA SWMM generates and provides output files for each manhole, pipe network and watershed. The urban runoff analysis module analyzes the derived result file and loads it into the database. Information derived from pipe network includes flow velocity, simultaneity, flow velocity, and water flow information, and information derived about manholes provides manhole water level, surface runoff, inflow information, and overflow information.

Among the information provided, this platform expresses overflow and water flow information about manholes and water pipe networks on the map as shown in Figure 9. On the map, the circle represents the manhole, and the color of the circle represents the degree of overflow, and the color changes from blue representing the normal to red as the discharge amount increases. On the map, the line represents the pipe network, and like a manhole, it changes from blue indicating normality to red as the water passage capacity increases.

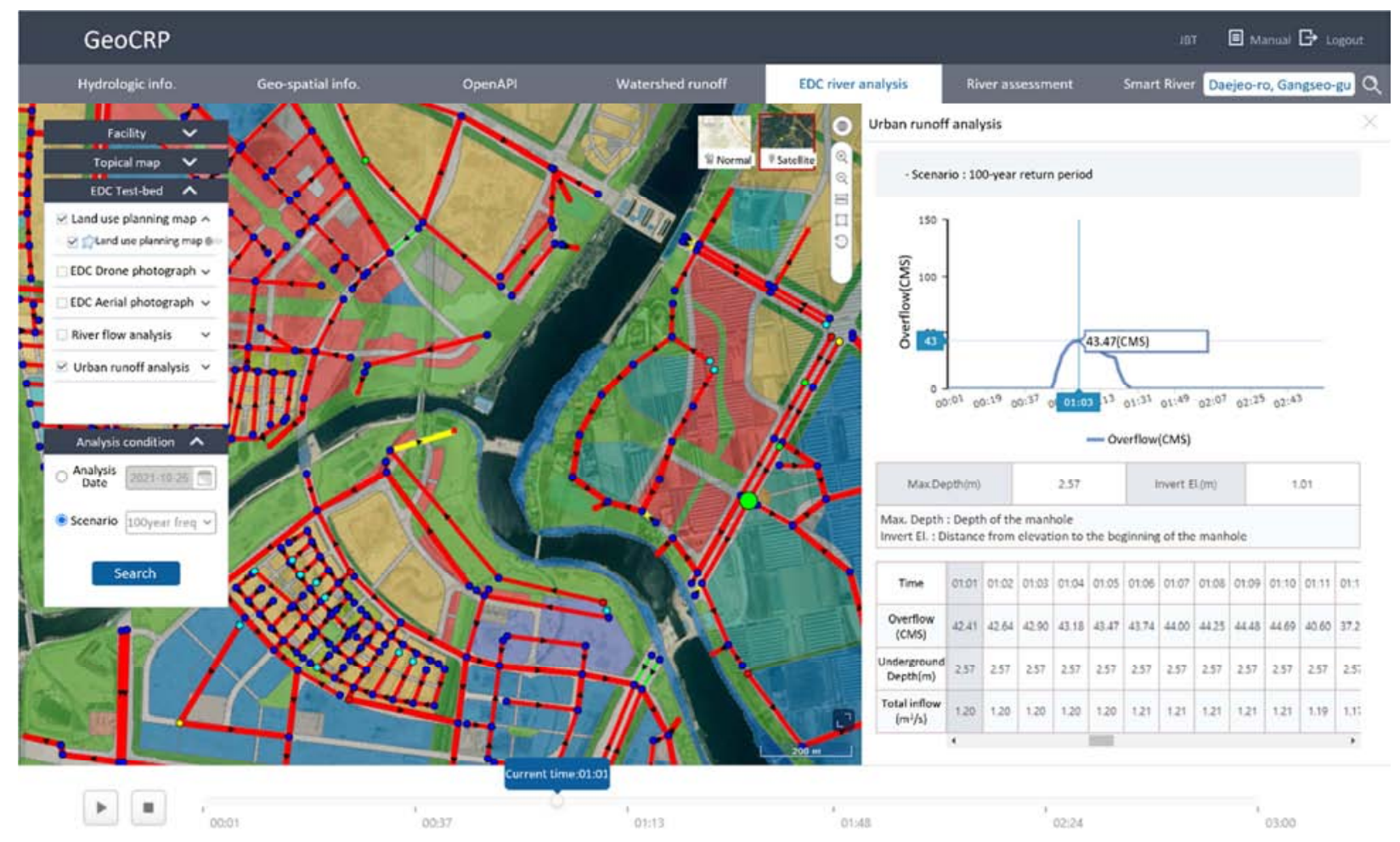

Figure 9. Urban Flow Analysis Result.

In addition, when a manhole or water pipe network is selected on the map, the selected manhole is marked with a lager circle and the selected pipe network is marked with a white border so that the selected point can be identified. For the selected items, as shown on the right of the figure, overflow information is provided for manholes and water flow information for water pipe networks as graphs. Specifications of pipe networks and manholes and time series information that change over time are provided in a table at the bottom right of the figure.

\section{Conclusion}

In this study, in order to perform urban runoff analysis for the EDC delta region, watershed runoff analysis module in the Nakdong River region, river flow analysis module of rivers around EDC and urban runoff analysis module in the target area were linked and developed within the platform. The developed platform analyzes the three modules based on 00:00 every day and stores the derived results in the database. The stored results can be viewed through this platform, and the animation function provides an intuitive way to check the changes in the analysis results during the analysis period.

In the current version of the platform, flood analysis was performed according to rainfall changes under actual environmental conditions. In future research, the platform will be upgraded so that users can perform flood analysis by adjusting various conditions based on actual environmental conditions. Through this, it is expected that it can be used as a pre-simulation data for urban development and to suggest solutions to overcome the assumed flood situation. 


\section{Acknowledgements}

This work is supported by the Korea Agency for Infrastructure Technology Advancement (KAIA) grant funded by the Ministry of Land, Infrastructure and Transport (Grant 21AWMP-B121100-06).

\section{References}

[1] Banasik, K.; Hejduk, A. Ratio of Basin Lag Times for Runoff and Sediment Yield Processes Recorded in Various Environments. In Proceedings of the International Association of Hydrological Sciences, New Orleans, LA, USA, 11-14 December 2014; pp. 163-169.

[2] Federal Emergency Management Agency (FEMA) and Harris County Flood Control District (HCFCD) (2002). Off the charts T. S. allison public report. Harris County Flood Control District, TX, U.S.

[3] Evans, E. P., and Von Lany, P. H. (1983). "A mathematical model of overbank spilling and urban flooding, Paper No. G5." International Conference on the Hydraulic Aspects of Floods \& Flood Control, London, U.K., pp. 241-255.

[4] Tate, E., and Maidment, D. (1999). Flood plain mapping using HEC-RAS and ArcView GIS. Center for Research in Water Resources, The University of Texas, Austin, T. X., U.S.

[5] Syme, W. J., and Paudyal, G. G. (1994). "Bangladesh flood management model." Proceedings Second International Conference on River Flood Hydraulics, York, U.K., pp. 167-176.

[6] National Weather Service (NWS) (1997). Automated local flood warning systems handbook weather service hydrology handbook No. 2. U.S. Department of Commerce, National Oceanic and Atmospheric Administra-tion, National Weather Service, Office of Hydrology: Silver Spring, M. D., U.S.
[7] Lee, H. L., Lee, J. W., and Kim, D. G., (1999). "Flood forecasting system and mapping using GIS." Journal of Civil and Environmental Engineering Research, Vol. 1999, No. 3, pp. 365-368.

[8] Bae, D.-H., Jeong, C., and Yoon, S.-s. (2008). "Development of flood prediction model using hydrologic observations in Cheonggye stream." Journal of The Korean Society of Civil Engineers, Vol. 28, No. 6B, pp. 683-690.

[9] Yoo, H.-H., Kim, W.-S., and Kim, S.-S. (2006). "Inundating disaster assessment in coastal areas using urban flood model." Journal of the Korean Society of Surveying, Geodesy, Photogrammetry and Cartography, Vol. 24, No. 3, pp. 299-309.

[10] Sathish Kumar, D.; Arya, D. S.; Vojinovic, Z. Modeling of urban growth dynamics and its impact on surface runoff characteristics. Comput. Environ. Urban 2013, 41, 124-135.

[11] Shin, H.-S., Jeon, S.-U., and Seo, B.-C. (2000). "Flood influence analysis on SUYOUNG River based on HEC-HMS/HEC-RAS." Journal of Korea Water Resources Association, Vol. 33, pp. 281-287.

[12] Shin, Hyunsuk, Park, Yong-Woon, and Hong, Ilpyo, (2007), "The Study on the Development of Flood Prediction and Warning System at Ungaged Coastal Urban Area - On-Cheon Stream in Busan -" Journal of Korea Water Resources Association, vol. 40, no. 6, pp. 447-458.

[13] Sin, Hyeon-Seok, Jeon, Seong-U, and Seo, Bong-Cheol, (2000), "Flood Influence Analysis on SUYOUNG River Based on HEC-HMS/HEC-RAS." Journal of Korea Water Resources Association, vol. 33, pp. 281-287.

[14] Ministry of Land, Infrastructure and Transport (MOLIT) (2012). West Nakdong basic river plan (changed) report. Busan Regional Construction and Management Office.

[15] Ministry of Land, Infrastructure and Transport (MOLIT) (2013). Nakdong basic river plan (changed) report. Busan Regional Construction and Management Office. 